\title{
Publisher Correction: Parallel genome reduction in symbionts descended from closely related free-living bacteria
}

Vittorio Boscaro, Martin Kolisko, Michele Felletti, Claudia Vannini, Denis H. Lynn and Patrick J. Keeling

Correction to: Nature Ecology \& Evolution https://doi.org/10.1038/s41559-017-0237-0, published online 21 July 2017.

The Supplementary Information file originally published with this Article was missing Supplementary Figs 1-7. This has now been corrected.

Published online: 27 February 2018

https://doi.org/10.1038/s41559-018-0484-8 